\title{
Luis Alberto Sánchez e os significados do latino-americanismo
}

\author{
Marcos Sorrilha Pinheiro ${ }^{1}$
}

\section{Resumo}

Analisando a história do pensamento latino-americano é possível reconhecer a existência de uma linhagem de atores políticos que, ao longo de suas trajetórias, defenderam a existência de um sentido nacional para a América Latina. Tal trajetória pode ser entendida como uma espécie de tradição e será por nós chamada de latinoamericanismo. Dentre os vários nomes que se apresentam como representantes dessa tradição latino-americanista, destacamos a figura do importante intelectual peruano Luis Alberto Sánchez (1900-1994). Sánchez fez parte de uma geração que lutou por ideais latino-americanistas e formulou uma linha de atuação política norteada pela mesma. Ao analisarmos o pensamento de Luis Alberto Sánchez, pretendemos aprofundar nossa compreensão a respeito do latino-americanismo e estudar algumas características fundamentais dessa tradição, ao mesmo tempo em que poderemos delimitar como Sánchez se encaixava na mesma.

Palavras-Chave: Identidade Nacional - Latino-americanismo - Luis Alberto Sánchez

\begin{abstract}
Analyzing the history of Latin American thought we can recognize the existence of a political actor lineage that, throughout their careers, have defended a national sense for Latin America. This lineage can be seen as a kind of tradition that we name Latin Americanism. Among the authors of this Latin-americanist tradition, we can highlight the Peruvian intellectual Luis Alberto Sánchez (1900-1994). Sanchez was part of a generation that have fought for Latin-americanist ideals and also have formulated a political action guided by it. Reviewing the thought of Luis Alberto Sánchez we wish to

\footnotetext{
${ }^{1}$ Doutor em História pela Unesp/Franca; Professor Assistente Doutor da Unesp/Franca, onde desenvolve o projeto de pesquisa intitulado Os grilhões coloniais: escravismo colonial e o processo de independência das Américas. Email: msorrilha@,franca.unesp.br
}

Revista Eletrônica da ANPHLAC, n.12, p. 230-253, jan./jun. 2012.

http://revista.anphlac.org.br/index.php/revista 
enhance our understanding of Latin-Americanism, study some fundamental characteristics of this tradition, and also define how Sanchez fits into it.

Key words: National Identity - Latin-Americanism - Luis Alberto Sánchez

\section{O latino-americanismo}

Desde os primórdios de seu processo de emancipação política, a elaboração de propostas para o futuro e para o desenvolvimento da América Latina ${ }^{2}$ se configura como tema central na história do pensamento político desse subcontinente. De certa maneira, ao longo dos últimos dois séculos, não foram poucas as tentativas de compreensão da América Latina e do latino-americano por parte considerável de intelectuais e políticos de diversos tipos e matrizes. Nesse percurso, em vários campos das ciências humanas, foram apresentadas análises que tomaram como objeto o homem e o espaço latinoamericanos, seus desafios e suas peculiaridades. No caleidoscópio de interpretações elaboradas, deparamo-nos com posições diversas sobre o tema, como: a negação da existência da América Latina, encarando-a como uma simples extensão da Europa; a América Latina subordinada, como uma zona de influência dos Estados Unidos; um "continente" autônomo e autossuficiente capaz de decidir sobre seu próprio futuro; entre outras.

A necessidade de estabelecer uma identidade ao subcontinente foi uma demanda própria do momento de emancipação política de seu território. Como sabemos, de modo geral, o século XIX foi um período em que a construção de identidades nacionais teve um papel de fundamental importância. Naquele momento, a passagem da Europa dos príncipes para a Europa das Nações obrigava a criação de um arcabouço de referências culturais e históricas que dessem às comunidades políticas uma ideia de continuidade pré-existente e independente da figura de seu monarca (THIESSE, 2001/2002). Entretanto, para o caso específico da América Latina, tal desafio apresentava alguns empecilhos. Como bem observam Aimer Granados García e Carlos Marichal (2004, p.11), “a complexidade do debate se deve, entre outros aspectos, a intersecção de diversas trajetórias e legados culturais que abarcam as tradições indo-americanas e afro-

\footnotetext{
${ }^{2}$ Sabemos que o conceito de América Latina é algo que se consolidou no debate intelectual, somente no século XX. No entanto, as discussões em torno de uma identidade para esse território é algo que remete ao século XVIII.
} 
americanas, a força ideológica e política dos Estados Unidos e a secular e múltipla herança cultural europeia". Assim, as tentativas de criação de identidades no subcontinente sempre levaram em consideração tais prerrogativas dos múltiplos referenciais políticos e culturais.

No peculiar no caso da América Latina, a elaboração de discursos identitários não se configurou como um processo exclusivo das nascentes nações do início do século XIX. No desmoronar da sociedade colonial espanhola, foi recorrente $\mathrm{o}$ aparecimento de interpretações que tentaram estabelecer uma unidade histórica e cultural a todo o subcontinente. Segundo Aimer Granados García (2004), naquele momento de quebra dos referenciais coloniais, o estabelecimento de identidades políticas na América Latina pressupôs a coexistência de três tipos de sentimentos de pertencimento: o hispano-americano, o protonacional e o provincial. Durante o processo de independência da América Espanhola, ocorreu uma tomada de consciência em torno das singularidades do continente como ponto fundamental para o distanciamento da influência europeia. Seria possível dizer que existiu um imaginário da 'americanidade', composto por elementos como a geografia, os mitos, a religião, a natureza e a história própria de nosso continente (GUERRA, 2000).

No entanto, ainda que a identidade continental aparecesse como uma opção, não foi ela quem se sobressaiu às demais. Na realidade, “[...] à medida que a construção estatal avançou com o século XIX, o pertencimento nacional foi se fazendo mais onipresente em cada país, até que no final do processo se impôs uma identidade política com nome próprio, colombiana, argentina, equatoriana etc.” (GARCÍA, 2004, p.39-40). Ocorre que a escolha pela formação de identidades locais não representou o fim da existência de uma vertente continental. Ao contrário, após a independência, o sentimento de pertencimento ao continente evoluiu e ganhou contornos de projetos coletivos que reverberou na literatura e na política de vários países de nosso território. Assim, tal demanda seguiu um curso próprio na história do pensamento latinoamericano, desenvolvendo-se em diversas etapas e, por isso mesmo, sendo ressignificada e reapropriada por diferentes grupos de intelectuais e políticos ao longo do tempo. Dessa feita, a defesa de um sentido coletivo para as ex-colônias americanas atravessou todo o século XIX e adentrou o século XX, encontrando entre intelectuais e 
políticos profundos defensores dessa proposta. A esse sentimento de pertencimento e defesa de propostas de união subcontinental, daremos o nome de latino-americanismo.

Em nossa interpretação, portanto, o latino-americanismo se configura como toda tentativa individual ou coletiva de construção de uma identidade nacional para a América Latina. Vale ressaltar que, enquanto elaboração intelectual, não podemos considerar o latino-americanismo como uma corrente de pensamento ou uma escola filosófica. Não existiu um movimento que assim se reivindicou. Por isso, é importante esclarecer que o latino-americanismo é uma criação teórica, que procura identificar, na trajetória do pensamento latino-americano, grupos políticos e intelectuais, que tinham um posicionamento favorável à interpretação da América Latina enquanto um bloco de Estados passíveis de identificação, seja por conta de seu legado sociocultural comum ou por intenções políticas/econômicas futuras. Na realidade, trata-se de um exercício de categorização analítica, que parte da premissa de que: analisando a história do pensamento latino-americano, é possível estabelecer uma linhagem de atores políticos que defenderam a existência de um sentido nacional para a América Latina. Tal afirmação nos possibilita estabelecer o latino-americanismo no âmbito das “comunidades imaginadas" (ANDERSON, 2008), ou das identidades nacionais (SMITH, 1998) ${ }^{3}$.

Assim, a temática da união continental não foi um objeto restrito ao início do século XIX, mas um constructo que foi constantemente reinventado ao longo da história política de nosso continente. Otavio Ianni observa muito bem que:

\begin{abstract}
a ideia de integração, ou confederação, não é nova. Nasce com as lutas pela independência e ressurge em diversas épocas, em cada país. Bolívar já havia posto claramente o problema. Martí fala em Nuestra América. Também Betances, Hostos, Sandino, Ingenieros, Haya de la Torre, Mariátegui, Guevara e outros reabrem o problema em seus escritos e suas lutas. [...] Ainda que em distintas perspectivas, preconizam a emancipação das sociedades nacionais no âmbito da integração, ou confederação, que as projetam; e favoreçam as suas potencialidades sociais, econômicas, políticas e culturais. (1995, p.106)
\end{abstract}

Se, no período da independência, o sentimento de pertencimento derivava de uma crescente tomada de consciência sobre si e da obrigatória necessidade de diferenciação perante o europeu, nos períodos que se seguiram à formação dos Estados

\footnotetext{
${ }^{3}$ A temática das comunidades imaginadas na América Latina, em um sentido mais amplo do que a tradição do latino-americanismo, foi muito bem explorada por Cláudia Wasserman em artigo intitulado Percurso intelectual e historiográfico da questão nacional e identitária na América Latina: as condições de produção e o processo de repercussão do conhecimento histórico, de 2003.
}

Revista Eletrônica da ANPHLAC, n.12, p. 230-253, jan./jun. 2012. http://revista.anphlac.org.br/index.php/revista 
Nacionais as motivações que levaram à sua retomada foram diversas. A própria denominação cambiante dada ao subcontinente demonstra tal afirmação. Com o passar dos séculos, essa região possuiu mais de “cem diferentes nomes" (ROJAS, 1991). Conforme é sabido, logo após a emancipação das ex-colônias espanholas, a referência terminológica ao novo bloco de Estados que surgia foi o de América, como aparece nos documentos do Congresso do Panamá de 1826. A adoção do termo demonstrava a deliberada vontade de se livrar da herança espanhola e afirmar o pertencimento exclusivo ao continente que abrigava aquelas nações. Após algumas décadas, em virtude da necessidade de se construir uma imagem de distanciamento em relação aos americanos do norte e de sua influência, o termo América ganhou um prenome que remontava a um passado comum àquelas nações e passou a ser referido como HispanoAmérica. Foi apenas a partir do último quartel do século XIX, que "a ideia de América Latina foi progressivamente se impondo sobre os outros conceitos" (GARCÍA, 2004, p.41). Assim, já no início do século XX, América Latina passou a ser o nome "oficial" dessa região, que compreende partes do hemisfério norte do continente, da América Central, do Sul e Caribe, incorporando outras ex-colônias para além das espanholas ${ }^{4}$.

Se, por um lado, os diversos nomes dados ao subcontinente demonstram as diferentes linhas de pensamento que incentivaram a elaboração de propostas para a América Latina, por outro, ele evidencia uma mesma vontade: encontrar um eixo primordial, capaz de subordinar as identidades locais à identidade latino-americana. Nesse sentido, ainda que as centenas de propostas de interpretações evidenciadas no latino-americanismo demonstrem tais divergências interpretativas, elas colocam tais grupos político-intelectuais em um mesmo campo de significação: a integração continental. Por conta disso, existiu, por parte de cada intelectual representante da linhagem latino-americanista, o esforço em delimitar tradições, valores e aspectos culturais tidos como tipicamente latino-americanos, que possibilitassem a união nacional e a sua afirmação diante das demais realidades nacionais. É evidente que essa linhagem de intelectuais a que nos referimos, alguns dos quais relacionados anteriormente no excerto de Ianni, possuem suas peculiaridades culturais e

\footnotetext{
${ }^{4}$ Justamente por conta do predomínio dessa alcunha sobre as demais, é que chamamos a todas as propostas que visam a estabelecer um sentido de nação ao subcontinente de latino-americanismo. Ainda que nem todas aceitassem o elemento "latino" como o fio condutor da história subcontinental, todas as interpretações faziam referência ao mesmo território que, historicamente, ficou reconhecido como América Latina.
} 
correspondem a contextos históricos e sociais amplamente distintos. No entanto, independentemente das diversas matrizes a que se vincularam, podemos notar que o que subsiste entre eles é a mesma leitura, ou seja, de que a união continental poderia se apresentar como um caminho para a superação dos problemas nacionais e supranacionais do continente.

Nesse sentido, o que os une é o latino-americanismo, a "crença" na realização de uma América Latina possível que, nesse caso, se materializou na temática da união continental. Vemos, por isso, que, para esses autores, os dilemas de suas sociedades deveriam ser pensados de maneira ampla e conjunta, extrapolando as fronteiras nacionais. Dentro dessa lógica, tais problemáticas, mais do que particularidades de cada localidade seriam o resultado de uma realidade comum e partilhada pelas demais nações, independentemente de sua bandeira. Tal realidade comum se manifestaria, por exemplo: no passado colonial de subjugação, na presença do(s) imperialismo(s), na pluralidade étnica, nas tradições autóctones, entre outros.

De tal maneira, podemos afirmar que o latino-americanismo se reproduz ao longo da história intelectual da América Latina, estabelecendo-se por meio de frequentes reiterações e se constituindo como uma tradição presente no pensamento e nas práticas políticas desse continente. Eis aqui um momento em que a criatura se equivale ao seu criador. Se, por um lado, o latino-americanismo representa a tentativa de elaboração de uma tradição inventada, nos dizeres de Hobsbawn (1984), o latinoamericanismo também o é. A estratégia de construção de uma continuidade histórica no exercício de se pensar a união latino-americana estabelece, para essa linhagem de intelectuais, uma espécie de tradição. Enquanto uma "tradição", o latino-americanismo busca estabelecer sua legitimidade, demonstrando a existência de um nexo histórico em suas formulações, como se fosse algo que possuísse raízes históricas anteriores à sua invenção ou reinvenção. Alimenta-se de referenciais do passado e faz reverência a determinados momentos e personagens históricos, como forma de ganhar autoridade e demonstrar a suas origens históricas, ou seja, a sua preexistência.

Seguindo tal expediente, justifica a sua validade, ao se apresentar como herdeira de acontecimentos como: as guerras de independência e as lutas revolucionárias; a subserviência do índio ao colono (ou ao estrangeiro); a exploração e a usurpação de terras, metais e riquezas; as raízes latinas, as raízes ibéricas, as raízes indígenas; o sonho 
bolivarista da união continental; o legado martiano; as lutas guevaristas; entre outros. $\mathrm{Na}$ tradição latino-americanista, temas como esses são retomados, apropriados, ressignificados e reinventados, na tentativa de promover uma relação de continuidade e ligação com um determinado passado e com determinados autores para, dessa forma, demonstrar a reivindicação histórica, presente em seus projetos e práticas políticas atuais.

O que tencionamos dizer é que a tradição latino-americanista se reproduz e se reinventa, como "reações a situações novas que, ou assumem a forma de referência a situações anteriores, ou estabelecem seu próprio passado, através da repetição quase obrigatória", conforme explica Eric Hobsbawn (1984, p.10). Por isso, é importante frisar que, mesmo que tais projetos sejam construídos com motivações diferentes e orientações políticas totalmente diversas, nutrem-se de equivalentes referenciais históricos, para confirmar a sua herança tradicional a um movimento, personagem ou acontecimento histórico, adaptando-os as suas necessidades. Assim, os atuais inventores de uma nação latino-americana parecem dar continuidade a uma mesma linha de pensamento iniciada ainda nas propostas bolivarianas, que defendia os mesmos interesses ao longo do tempo, quando sabemos que é justamente o oposto. Dessa feita, é necessário esclarecer que, mais do que um latino-americanismo, o que existe são latinoamericanismos, no plural, no sentido de que as interpretações positivas a respeito da América Latina são também diversas. Nutrem-se de referenciais iguais, mas dando uma nova leitura para tais eventos ou elementos históricos, adequando-os aos interesses dos grupos ou dos movimentos políticos aos quais estão servindo, sendo que, por diversas vezes se negam, mesmo quando estão reelaborando um ao outro.

Um exemplo que podemos usar para ilustrar a reprodução da tradição do latinoamericanismo na política latino-americana é a imagem de Simón Bolívar. José Martí dedicou alguns textos ao elogio dessa figura libertária. Victor Raul Haya de la Torre retomou Bolívar para construir seu ideal aprista de defesa continental frente ao imperialismo ${ }^{5}$. Recentemente, Hugo Chávez também proferiu repetidos discursos sobre

\footnotetext{
${ }^{5}$ Aprista ou aprismo se refere à APRA (Aliança Popular Revolucionária Americana). Percebam que a APRA se apresenta como um movimento americano, sem distinção de país. A APRA possui uma atuação histórica no Peru, se constituindo, hoje, como o partido mais importante do país. No entanto, ao longo de sua trajetória, desempenhou atividades políticas na Argentina, no Chile e no México, possuindo diretórios espalhados em vários países. A fundação da APRA por um peruano Haya de La Torre, no México, é um bom exemplo disso.
} 
a não submissão da América Latina frente ao contexto mundial, sob os auspícios do "mártir revolucionário" que se reproduz em monumentos espalhados em incontáveis vezes pela Venezuela ${ }^{6}$. Todos os personagens mencionados defenderam posições positivas frente ao continente e viram na união continental uma saída para a solução de problemas de seu contexto. No entanto, é claro e evidente que os três projetos políticos são distintamente opostos entre si, diferenciando-se até mesmo do que inicialmente foi proposto por Bolívar. Porém, mesmo que se filiem a correntes políticas distintas, utilizam-se da figura do "libertador" para corroborar suas intenções continentais e estabelecer um vínculo com o passado comum. Por isso, frequentemente, quando se propõe uma unificação para a América Latina, independente do espaço-tempo, a figura de Bolívar é retomada, ainda que as bases, o entendimento dos motivos e as diretrizes para o projeto sejam díspares em relação àquelas pensadas pelo venezuelano. Bolívar, ou melhor, a associação do ideal unificador atribuída a Bolívar, é uma marca recorrente da tradição latino-americanista. Assim, as propostas de integração continental, ao retomarem um passado comum, semelhanças geográficas ou figuras históricas, procuram estabelecer um sentido de continuidade a uma tradição que supostamente teria sido construída, desde o processo de independência da América Latina com Bolívar, de maneira a se postarem como partes integrantes de uma linhagem latino-americanista.

Dentre os vários nomes que se apresentam como representantes dessa tradição latino-americanista, podemos destacar a figura do importante intelectual peruano Luis Alberto Sánchez. Em nossa concepção, Sánchez fez parte de uma geração que lutou por ideais latino-americanistas e procurou formular uma linha de atuação política norteada pela mesma. De maneira geral, sua geração, a vanguarda intelectual latino-americana, foi protagonista de um momento em que a ideia de "um nacionalismo para o continente", traço destacável do latino-americanismo, ganhou maior força. Desde o movimento que marcou a "fundação" dessa geração, a Reforma Universitária de 1918, em Córdoba, na Argentina, a interpretação de um sentido único para o continente já

\footnotetext{
${ }^{6}$ Mais uma vez, advertimos que não queremos aqui reunir esses autores em um único grupo de maneira uniforme. Reconhecemos as diferenças existentes em seus pensamentos e ações políticas. No entanto, entendemos ser possível identificar traços de similaridades entre eles, por se tratarem de atores que reproduziram a tradição do latino-americanismo, recorrendo à utilização de um antepassado histórico, nesse caso: Bolívar.
}

Revista Eletrônica da ANPHLAC, n.12, p. 230-253, jan./jun. 2012. http://revista.anphlac.org.br/index.php/revista 
estava posto ${ }^{7}$. Além disso, o aprismo, movimento político criado com o intuito de constituir uma frente de ação política que representasse os anseios dessa geração, também propunha, de maneira explícita, esse "nacionalismo" continental ${ }^{8}$.

Nesse sentido, por ser um dos membros de destaque de sua geração, um dos líderes da Reforma Universitária peruana e um dos principais ideólogos do aprismo, pensamos que, ao analisarmos o pensamento de Luis Alberto Sánchez poderemos aprofundar nossa compreensão a respeito do latino-americanismo e estudarmos algumas características fundamentais dessa tradição. De outra maneira, poderemos delimitar como Sánchez se encaixa nessa tradição, apropriando-se dos elementos que a compõem, dando novos significados a seus símbolos ou incorporando novos elementos a ela.

\section{O latino-americanismo em Luis Alberto Sánchez}

Luis Alberto Sánchez nasceu em Lima, no Peru, em 12 de outubro de 1900. Seu interesse pela política teve início juntamente com seu ingresso na lendária Universidade de San Marcos, no ano de 1917, para cursar a faculdade de Letras. Em 1919, participou ativamente da Reforma Universitária ocorrida em seu país. Doutorou-se em Letras ainda muito jovem e deu início a sua carreira de professor universitário, em 1926, pela mesma universidade onde se graduou. Sua entrada para a política partidária ocorreu no ano de 1932, depois que o aprismo se converteu em um partido legalmente constituído no Peru (PAP - Partido Aprista Peruano). A partir de então, Sánchez dedicou sua vida política à construção, idealização e reconhecimento do partido como uma das principais forças políticas de seu país e da América Latina. Foi deputado, senador e vice-presidente do Peru, configurando-se como a principal referência histórica da APRA depois de Victor Raul Haya de la Torre, seu fundador. Sua produção literária foi tão extensa quanto sua vida, deixando mais de cem obras publicadas. Sánchez faleceu no ano de 1994, após

\footnotetext{
${ }^{7}$ Durante a Reforma Universitária de Córdoba, nos documentos oficiais do movimento, os alunos, liderados por Gabriel del Mazo, escreviam que, naquele momento, estavam vivendo uma "hora americana". Acreditavam que, ao questionar a organização do sistema universitário latino-americano, questionavam também a própria estrutura social da América Latina. Ver: TOLEDO, Patrícia Renata de. Reforma universitária na América Latina (Argentina e Peru): a emergência das vanguardas no continente. Franca, 2000. Dissertação de Mestrado em História - Unesp.

${ }^{8}$ Para entender esse momento de efervescência latino-americanista, indicamos a leitura de FUNES, Patricia. Salvar la nación. Intelectuales, cultura y política en los años veinte latinoamericanos. Buenos Aires: Prometeo, 2006.
} 
uma vida de frequente exílio e muita dedicação à política e à vida acadêmica em todo continente latino-americano ${ }^{9}$.

Ao observarmos sua vasta produção intelectual, percebemos que um dos temas recorrentes é justamente a busca pela elaboração de uma identidade comum para os países latino-americanos, principalmente entre as décadas de 1930 e $1940^{10}$. Nas interpretações de Sánchez sobre o continente, persiste um posicionamento positivo frente à realidade latino-americana como uma forma de encontrar um nexo identitário, capaz de unificá-lo e constituí-lo como um forte bloco político e econômico. Encontramos, portanto, elementos que o qualificam como um representante do latinoamericanismo. Em outras palavras, podemos afirmar que Sánchez se apresenta como um ideólogo da América Latina, uma vez que buscou conceituá-la e prover-lhe de um sentido teórico.

Em sua trajetória, a busca pela compreensão do continente não apenas foi recorrente como também intensamente vivida. Muito mais do que um propositor de interpretações ou teorias sobre a realidade latino-americana, percebemos em Sánchez alguém que se posicionou como um propagador de uma América Latina real e possível, tanto por sua atividade junto à APRA, quanto pelas constantes viagens feitas para outros países latino-americanos, quer fosse para participar de palestras ou eventos políticos, quer pela frequente vida em exílio. Para ele, a América Latina não só existia, como deveria buscar incessantemente sua própria afirmação. É esse argumento marcante que aparece na obra Existe América Latina?, de 1945, como vemos nesta citação:

Sem [...] metáfora oratória, temos em nossas mãos a responsabilidade de reedificar a cultura do globo, de dar forma a um novo mundo. Estamos em dívida, já não com o ontem, senão com o hoje e o amanhã. [...] Forjaremos e dignificaremos nosso papel somente na medida em que soubermos nos erguer sobre tanto prejuízo que ainda nos subjuga, e à medida que nos encarnarmos, com mente virgem, ao imediato - sempre tão confuso e estranho -, e darmos passagem às responsabilidades humanas, sobre arrogâncias e mesquinharias próprias de uma sociedade sem esperança, entre as disputas do passado, por

\footnotetext{
${ }^{9}$ Para conhecer mais sobre a vida e obra de Luis Alberto Sánchez indicamos: SALVATTECCI, Hugo Garcia; MIRANDA, Marlene Polo. Luis Alberto Sánchez, la vida del siglo. Caracas: Editora Ayacucho, 1987.

${ }^{10}$ Acreditamos que a maior incidência nesse período se deva à própria efervescência do tema entre os intelectuais latino-americanos. A "hora americana", propagada desde a Reforma Universitária, foi item fundamental nas discussões entre os intelectuais da "vanguarda revolucionária". Trata-se de um momento de afirmação da realidade latino-americana em um contexto de crise dos modelos culturais e econômicos europeus e norte-americanos, bem como o surgimento de novas forças políticas como o comunismo soviético e eventos internos de profunda importância, como a Revolução Mexicana. Neste artigo utilizaremos, fundamentalmente dois livros: Existe America Latina? de 1945 e Vida y pasión de la cultura en America de 1935.
} 
falta de capacidade, de força e de valor para encarar o obrigatório futuro. (SÁNCHEZ, 1968, p. 227) $)^{11}$

Luis Alberto Sánchez foi um intelectual que buscou o entendimento, a afirmação e a superação dos dilemas da América Latina, podendo ser considerado um representante da linhagem latino-americanista. Então, quais seriam as principais características desenvolvidas pelo latino-americanismo no pensamento do nosso autor?

Em nossa concepção, a principal e fundamental característica do latinoamericanismo no pensamento de Luis Alberto Sánchez é a mestiçagem ${ }^{12}$. O mestiço aparece para Sánchez como a esperança de unidade, como a representação da "heterogeneidade que homogeneíza". Enquanto chave para a interpretação da América Latina, o mestiço representava o traço de unidade presente entre os países que a compunham. Para Sánchez, a unidade latino-americana nascia justamente de suas diferenças, tal como no caso do mestiço. Afirmou o autor: "um sotaque uniforme os une. (...) Nossa sinfonia surge, assim, de nossas próprias desarmonias. São essas, mais do que nada, as que definem nossa personalidade continental" $(1970, \mathrm{p} .11-12)^{13}$.

É necessário esclarecermos que, quando se refere ao termo sinfonia, Sánchez deixa claro que, assim como uma orquestra é formada por diversos instrumentos (sejam eles de corda, sopro ou percussão, mas diferentes entre si), que quando agrupados e bem conduzidos se tornam um conjunto uniforme, o mesmo deveria ocorrer com a América Latina: uma união de diferentes elementos que, juntos, possuíam sincronia e papéis específicos a serem desempenhados em prol de um todo, a favor de uma harmonia. Talvez outra metáfora desenhada por Sánchez expresse melhor e sublinhe o que pretendemos explicar:

As discrepâncias são adjetivas e justificam a unidade. Se nos poemas clássicos, para que a unidade fosse mais efetiva, se requeria multiplicidade de episódios, também para a solidariedade de um continente necessita-se de uma disparidade de orientações. O uno vive dos vários. (1970, p.37)

\footnotetext{
${ }^{11}$ Apesar da referência indicar o ano de 1968, gostaríamos de esclarecer que a primeira versão do livro data de 1945.

${ }^{12}$ Sánchez não faz referência a um tipo de mestiço específico, bem como às etnias envolvidas no processo de mestiçagem. Segundo entendia, independente dos tipos de mesclas "raciais", o grande mote da América era o fato de essa ser o território da mestiçagem, e o seu povo oriundo do encontro de "raças". A defesa da mestiçagem se dá de maneira genérica e não por um tipo de encontro étnico específico.

${ }^{13}$ Da mesma maneira, apesar da referência indicar o ano de 1970, a primeira versão é de 1935.
} 
Da mesma maneira que a orquestra é única apesar de plural, o mesmo ocorre com os épicos literários. Tendo essa concepção de unidade, não poderia ser outro elemento de identidade latino-americano eleito por Sánchez que não o mestiço, representação máxima dessa diferença, novamente: a heterogeneidade que homogeneíza. Justamente por isso, afirmava que o mestiço era "a verdadeira encarnação da América" (Idem, p.89), a chave para a compreensão do continente latino-americano. O mestiço seria a representação da grande mistura em que consistia a América Latina. Mescla não apenas de "raças", mas também de credos, costumes, tradições, folclores e valores que se transformaram nesse polissêmico continente.

A questão da mestiçagem em Luis Alberto Sánchez é algo que merece ainda mais algumas observações. De certa maneira, ao recorrer à figura do mestiço como elemento subjacente a todas as tradições latino-americanas, Sánchez assumia a dificuldade de se criar um mito preexistente diante das várias referências culturais existentes no continente, como mencionamos anteriormente. Em seu entendimento, na América, o artifício de se estabelecer uma origem étnica comum, uma comunidade primordial resultaria em interpretações incompletas. Assim, como prática comum do exercício de inventar identidades, buscou a unidade em um passado comum, representado não por um evento ou por um mito de origem, mas sim pelas interações étnicas, marca distintiva do continente perante os demais.

De outra forma, é interessante notarmos que a utilização da mestiçagem como um recurso para a afirmação de uma unidade não era prática comum entre os intelectuais peruanos daquele mesmo momento. Entre seus pares, a discussão que estava posta era pautada pelo 'indigenismo' da década de 1920 e, por isso, a concepção mais atribuída à unidade continental era a do Indo-americanismo, como aparece em José Carlos Mariátegui ou em Haya de la Torre e outros tantos membros do aprismo. A propósito, sobre a própria discussão do 'indigenismo' no Peru, Sánchez apareceu como um opositor de tal corrente, desenvolvendo uma profícua polêmica com Mariátegui, ainda em 1927 (CASTRO, 1976). De qualquer maneira, a utilização da mestiçagem como elemento de unidade não foi uma novidade trazida por Sánchez. Ao contrário, era algo que já vinha sendo desenvolvido por outros intelectuais latino-americanos daquele mesmo período, como Gilberto Freyre, no caso do Brasil, e do mexicano José Vasconcelos, com os quais o peruano teve contato. 
Sem dúvida, o mestiço e a mestiçagem são os pontos fundamentais que norteiam o pensamento desse autor. Porém, outras características demarcam o latinoamericanismo presente em suas formulações e que agora dedicaremos mais atenção. Se a mestiçagem é um ponto que o afasta dos demais peruanos, o anti-imperialismo é algo que o aproxima de sua geração vanguardista e do aprismo. Sánchez, como boa parte da vanguarda, adotou uma postura anti-imperialista bastante clara: qualquer intervenção externa na América Latina deveria ser severamente refutada, principalmente as de origem norte-americana. Percebemos esse posicionamento, quando, em suas obras retomava as invasões norte-americanas à Nicarágua, na década de 1920. Seus ataques, bem como a condenação das práticas militares norte-americanas, chegaram a ponto de o autor afirmar que tudo isso mexia diretamente com um sentimento bélico que trazia dentro de si (SÁNCHEZ, 1968). Suas críticas não se restringiam ao imperialismo militar; o imperialismo econômico também era visto como algo danoso. Para o autor, dentro do processo de desenvolvimento histórico da América Latina no século XX, o imperialismo, em associação com as elites locais, representou a origem do atraso e da má formação das economias e nações latino-americanas. Seguindo o argumento primordial de sua geração, para a América Latina o imperialismo não era a etapa final do capitalismo no mundo, como defendiam os soviéticos, mas sim o seu início.

Cabe esclarecer que o anti-imperialismo exacerbado no pensamento de Luis Alberto Sánchez não representava, contudo, uma atitude cega. Existia uma constante alteração de ânimos com relação aos Estados Unidos, à medida que se desenrolou a sua extensa trajetória biográfica. Na própria década de 1930, por exemplo, tal posicionamento bélico perdeu força, com a política da "Boa Vizinhança" implantada pelo presidente norte-americano Franklin Roosevelt. Tal "prática" levaria inclusive a própria APRA e suas principais lideranças a revisarem seus conceitos quanto ao antiimperialismo. Como nos sugere Oliveiros Ferreira (1971, p.264), “quando se propõe o New Deal e a política da 'Boa Vizinhança', o aspecto econômico do imperialismo perde para ele [Haya de la Torre] em importância decisória". Assim, a retração das políticas intervencionistas norte-americanas provocou de imediato uma retração do antiimperialismo aprista, já que, aparentemente, o posicionamento frente às ações imperialistas norte-americanas, por parte da APRA, sempre foi de defesa e sobrevivência - não de ataque. Ademais, Sánchez nunca se posicionou "contra" os 
Estados Unidos, nunca foi um antinorte-americano, mas sim contra o imperialismo norte-americano e a favor da América Latina, o que são coisas bem distintas.

De qualquer maneira, a relação de amor e ódio com os Estados Unidos foi outro item importante para a formulação do latino-americanismo em seu pensamento. Nos textos que fazem referência aos EUA, os norte-americanos sempre são abordados com certa admiração. Entre outras características, Sánchez admirava a democracia, o desenvolvimento industrial e a grande potência em que os Estados Unidos havia se tornado. Não surpreendentemente a admiração de Sánchez pelos Estados Unidos também se relacionava com a temática da mestiçagem destacada anteriormente. Para ele, os Estados Unidos representavam a vitória do mestiço. Segundo o autor, foi nos lá que o mestiço se reconheceu enquanto agente protagonista e não o simples resultado do "encontro violento de raças", o que ficaria claramente representado no momento da “corrida para o oeste", seu maior triunfo. Segundo argumentou o peruano, o povoamento do centro-oeste norte-americano permitiu o crescimento de pessoas comuns, oriundas de vários cantos da Europa. De outra forma, essa mescla de culturas exigiu a construção de mecanismos democráticos de organização sociais mais complexos e que permitissem a convivência de valores e tradições tão diferentes.

Destarte, em suas formulações sobre a América Latina, por diversos momentos, Sánchez se utilizou dos Estados Unidos como padrão de comparação, um tipo ideal e, podemos até sugerir, que esse aparecia como modelo a ser atingido. Talvez Sánchez sofresse, como classificou Richard Morse, de um certo 'encantamento' por observar durante séculos a imagem do próspero, os Estados Unidos, refletida em um espelho voltado para si (MORSE, 2000, p.42). Algo como: “deveríamos ser como eles, mas sem a sua ajuda”, ou melhor, “deveríamos ser como eles, mas à nossa maneira”.

Ao traçarmos as primeiras características do latino-americanismo, presentes em Luis Alberto Sánchez, a mestiçagem, o significado dos Estados Unidos e o antiimperialismo, percebemos que o último, em particular, coincide tanto no pensamento de Sánchez quanto no pensamento de outro importante latino-americanista representante da mesma geração: Victor Raúl Haya de la Torre. De certa forma, como já deixamos a entender, existem muitos pontos em comum entre Sánchez, Haya de la Torre e os demais apristas de sua geração. Tal afirmação nos conduz a uma pergunta associativa e que nos ajudará avançar em nossas análises: a interpretação positiva da América Latina, 
gerada pelo latino-americanismo presente no pensamento de Luis Alberto Sánchez, não pode ser considerada a mesma apresentada por Haya de la Torre? Afinal, ambos foram amigos pessoais, fizeram parte de um mesmo partido e compartilharam uma ideologia de atuação política, além de pertencerem à mesma geração intelectual?

Acreditamos que a resposta para as interrogações seja negativa. Existem evidentes congruências entre os dois personagens, assim como também entre outros. $\mathrm{O}$ anti-imperialismo, por exemplo, era uma questão da ordem do dia, durante o início do século XX, presente não apenas entre os apristas, mas entre os comunistas, socialistas e até entre aqueles que seriam depois rotulados pelas ciências sociais de populistas. Afinal de contas, essa comunhão de valores reforça ainda mais nossa hipótese de existência de uma tradição latino-americanista.

Porém, efetivamente, ao analisarmos criticamente, perceberemos que as suas diferenças se sobressaem, principalmente à medida que conhecemos melhor cada um dos autores. De maneira superficial, podemos notar uma diferença de perfil, que se apresenta na formação intelectual de ambos. Sánchez era um latino-americanista de perfil acadêmico, que postulava suas teorias dentro de um contexto de discussão e debate científico. Haya de la Torre, por sua vez, era um latino-americanista de perfil mais prático, muito mais ligado às funções orgânicas proporcionadas pela política, de modo que sua discussão beirava a ação.

Quanto ao conteúdo de suas formulações latino-americanistas, encontraremos diferenças substanciais que precisam ser esclarecidas. Para Haya de la Torre, o problema da América Latina residia no indígena. O passado histórico de sofrimento, subjugação e exploração pelo qual passou o indígena deveria servir de inspiração para o continente, enquanto explorado, na sua afirmação frente ao mundo. O sofrimento do indígena seria o sentimento de nivelamento comum aos países latino-americanos, historicamente subjugados, segundo sua interpretação. Por conta disso, Haya de la Torre se considerava um adepto do indo-americanismo. Por pensar assim, criou um modelo de classificação, no qual associava as diversas denominações que a América Latina sofreu ao longo de sua história com a sua condição de constante exploração histórica. Assim, Hispano-América fazia referência à sua época colonial; América Latina era equivalente ao período da Independência e República; Panamérica, o imperialismo e; Indoamérica a representação de integração e liberdade (CASTRO, 1996). 
Já em Luis Alberto Sánchez, como vimos anteriormente, seria o mestiço e não o indígena a chave para a compreensão da América Latina. A aceitação do indígena como centro de interpretação da realidade latino-americana restringia muito as potencialidades da análise e as possibilidades de se estabelecer uma identidade única. Assim, Sánchez refutava até mesmo a utilização do termo Indoamérica para a caracterização do continente e das ilhas. Para nosso autor, Indoamérica era uma "expressão não muito exata, representativa de um movimento reivindicatório dos explorados contra seus exploradores" (SÁNCHEZ, 1968, p.83). Sobre tais prenomes, é interessante a sua observação de que a adoção do mestiço como elemento de identidade e fundamento da unidade acarretava na imediata negação de qualquer outra denominação que vinculasse o continente a algum povo ou etnia específica. Justamente por isso, para Sánchez, a América Latina deveria ser conhecida apenas como América, não como Indoamérica e muito menos América Latina. Justificando-se: “este vocábulo deve ser libertado da absurda limitação 'latina' que nele é translúcida. Ser americano não é ser saxoamericano, nem tão pouco ser nada mais que indoamericano” (Idem, p.29).

Mesmo com esse preterimento à denominação "América Latina” em referência ao continente, acreditamos que seja possível classificá-lo como um latino-americanista. Afinal, a busca pela afirmação do continente - prerrogativa maior do latinoamericanismo - era o principal objetivo de suas formulações, não importando qual denominação que a ele fosse imputado. Tal interpretação pode ser confirmada quando recorremos às seguintes palavras do autor:

\begin{abstract}
talvez teria que recomeçar desde o nome, deixando que sua vigência nasça da realidade, em lugar de nos prendermos em bizantinos debates tão do agrado de historiadores e 'leguleios'. Porque o importante - chamem-nos América Latina, Iberoamérica, América hispana, Indoamérica, Panamérica, Interamérica, Indoibéria, ou como quiserem - o importante é que sejamos - e já somos. Tanto ou mais velhos do que os asiáticos e os europeus, à luz dos mais recentes descobrimentos arqueológicos, constituímos, apesar disso, um Novo Mundo, por nossa estreia na influência universal, por nosso descobrimento do destino. (1968, p.227)
\end{abstract}

Assim, por meio deste excerto, fica claro que Sánchez preferia a utilização de alguma denominação que não vinculasse o continente a nações ou etnias, algo como América ou até mesmo a recorrência a um novo nome. Porém, mais assertivo e importante do que isso foi a busca pela afirmação do continente.

Revista Eletrônica da ANPHLAC, n.12, p. 230-253, jan./jun. 2012. http://revista.anphlac.org.br/index.php/revista 
Dando continuidade às delimitações propriamente ditas do latino-americanismo em Luis Alberto Sánchez, frente ao que já apresentamos até aqui, é plenamente possível afirmar que ele postulava sua crença na existência de uma América Latina enquanto realidade histórica. Para Sánchez, existia um forte movimento no pensamento político europeu e norte-americano que trabalhava na afirmação de que a América Latina não existia. Conforme argumentava, a ideia de que a América Latina não existia seria um construto ideológico e não o contrário. Portanto, isso ocorria propositadamente, para que o subcontinente não se reconhecesse como uma grande potência e, assim, não se colocasse assertivamente frente às demais. Nesse sentido, como na esgrima, que reúne ataque e defesa em movimentos quase simultâneos, Sánchez sugeria que as mesmas prerrogativas e questionamentos utilizados para a refutação da existência da América Latina fossem utilizadas para a averiguação da existência da Europa e dos Estados Unidos como modelos de união e realidades históricas válidas.

De tal forma, utilizando-se da mesma lógica argumentativa aplicada à América Latina, o autor chegou à conclusão de que os Estados Unidos também não existiam. Não existiam, pois, assim como a América Latina, tinham sido uma colônia que possuiu o seu passado histórico atrelado ao continente europeu; não possuíam um traço físico e estético único, devido à sua múltipla colonização e mestiçagem; tinham o seu território dividido em diversas realidades, não podendo ser definidos como iguais os estados de Nova York e Alabama, Flórida e Califórnia, entre outros. Do mesmo modo, pensando na Europa, observou que essa foi formada a partir das invasões germânicas de diversos clãs e povos ou, até mesmo, da invasão moura ao sul da Península Ibérica, trazendo concepções e dialetos orientais e externos à realidade europeia, que demarcariam um traço de impossível unidade. Não existiria, portanto, uma cultura puramente europeia. Em síntese, o conceito de Europa enquanto unidade concreta tampouco seria válido.

Sánchez encerrava seu argumento, afirmando que as mesmas condições que permitiam afirmar que a Europa e os Estados Unidos existiam enquanto realidade histórica poderiam ser encontradas na América Latina. Assim, se os Estados Unidos e a Europa fossem tomadas como "modelos" de unidade, homogeneidade e cooperação, não haveria porque não rotular a América Latina dessa maneira. Da mesma forma, os elementos desagregadores detectados no subcontinente também poderiam ser encontrados na Europa e nos EUA, como a própria mestiçagem. O interessante desse 
exercício de argumentação de Sánchez não reside em sua validade ou não. O que nos chama a atenção é o fato de o autor comparar a América Latina aos Estados Unidos, que é um Estado-Nação no sentido mais estrito do termo. Dessa feita, ao trazer os dois ao mesmo plano, em nossa maneira de entender, torna plausível a defesa da América Latina enquanto nação.

Isso posto, caberia aos intelectuais e cidadãos latino-americanos, e Sánchez os convocava a isso em seus escritos, combaterem a pressão ideológica europeia, que não passava de uma contradição flagrante e de uma armadilha conceitual que visava unicamente a desunir ainda mais a América Latina. Reconhecer a existência da América Latina seria um primeiro e fundamental passo para sua imposição perante o mundo. Para Sánchez, a falta de reconhecimento da unidade por parte dos latino-americanos levava ao isolamento de seus países. Assim, Sánchez acreditava que havia uma maior comunicação e intercâmbio entre os países da América Latina e os Estados onde do que entre eles mesmos, como se esses países desempenhassem isoladamente seu lugar no território latino-americano, negando-se constantemente e cegos a suas similitudes.

Ao longo de sua obra, para defender a unidade latino-americana, Sánchez fez referências a outros autores da linhagem latino-americanista. Entendemos que tal expediente representa a tentativa de legitimar seus argumentos retomando uma tradição do pensamento latino-americano, como vimos anteriormente. Assim, lendo seus livros encontramos referências a Bolívar, Rodó, Haya de la Torre, José Carlos Mariátegui, José Vasconcelos, entre outros. No entanto, dificilmente encontramos uma citação direta dos textos de Martí. Essa constatação nos leva a uma última pergunta em torno do latino-americanismo de Sánchez: por que José Martí raramente foi citado como suporte teórico ou metodológico pelo autor? Por que José Martí, importante figura do latinoamericanismo, representante do "grito de independência" da Nuestra América, não aparece na construção de um posicionamento favorável à América Latina nos quadros do pensamento de Sánchez ${ }^{14}$ ?

É evidente que uma primeira possibilidade diz respeito à própria visibilidade que Martí possuía para os autores daquele momento. É inegável que as ideias de Martí e

\footnotetext{
${ }^{14}$ Não se trata aqui de fazer uma simples comparação entre Luis Alberto Sánchez e José Martí. O que tencionamos é fazer uma aproximação histórica entre as propostas feitas pelos dois autores aos destinos do continente. Apontar as diferenças é também uma forma de demonstrar como o latino-americanismo é reinventado e ressignificado de acordo com as demandas, contextos e intérpretes que o propõe.
} 
uma leitura que o toma como propositor de uma ruptura com o ocidente somente tomaram corpo após a Revolução Cubana de 1959. De certa maneira, Martí passou a ser incorporado à "genealogia" construída pela Revolução Cubana para dar-lhe um sentido de continuidade aos movimentos revolucionários anteriormente ocorridos na ilha. De qualquer maneira, Martí não era um personagem desconhecido dos principais nomes da vanguarda intelectual, e Sánchez se encontrava entre eles. Nesse sentido, para tentar resolver esse problema, pensamos que nossa pergunta deva ser outra: por que Sánchez deveria recorrer a Martí para apoiar suas interpretações sobre a América Latina?

Ainda que essa pergunta pareça deslegitimar aquelas feitas anteriormente, ela nos permite estabelecer um distanciamento entre aquilo que propôs Martí e aquilo que estabeleceu Sánchez. Nesse sentido, por meio da comparação, fica ainda mais claro visualizar as principais propostas do peruano. Posto isso, em nosso entendimento, ao contrário de Martí, Sánchez não pregava um sentido de descontinuidade com o pensamento ocidental, não acreditava que um rompimento teórico e conceitual com modelos ocidentais fosse o melhor caminho a ser adotado. Nas proposições de Sánchez, não se apresentou a América Latina como uma 'sociedade alternativa', mas sim diferente. Não havia a negação da continuidade histórica da América com o passado europeu, na tentativa de tirar a América Latina da história ocidental. Até mesmo porque isso representaria a negação de seu argumento central: a mestiçagem.

Desse modo, acreditamos que, apesar de os dois autores apontarem a necessidade de uma união latino-americana e de serem representantes do latino-americanismo, seus projetos para a América Latina foram muito distintos entre si. Martí propunha que a América Latina, ou simplesmente a Nuestra América, deveria passar a formular seus próprios conceitos e modelos teóricos, deixando de lado as fórmulas de afuera, que se constituíam em grandes erros para o continente e que, por isso, deveriam ser superados. Conforme defendia, "nossa América está se salvando de seus grandes erros - da soberba das cidades capitais, do triunfo cego dos camponeses desdenhados, da importação excessiva das ideias e das fórmulas alheias" (MARTí, 1991, p.198).

A luta de Martí contra a apropriação de conceitos externos partia do pressuposto de que eles não se encaixavam e nem conseguiam explicar a realidade da Nuestra América. Dessa maneira, o rompimento com tais modelos deveria partir de suas bases, ou seja, da não importação e não aceitação, por exemplo, de suas universidades. Martí 
defendia que a América Latina não deveria assumir seu passado de colonização, mas sim seu passado indígena, e isso era um ponto de total ligação com a educação aplicada em nosso continente. Segundo ele, "a universidade europeia deve dar lugar à universidade americana. A história da América, dos incas para cá, deve ser ensinada minuciosamente, mesmo que não se ensine a dos arcontes da Grécia. A nossa Grécia é preferível à Grécia que não é nossa" (Idem, p.197). Em sua visão, a América Latina deveria despontar como uma sociedade alternativa e, a partir dela, deveria se fundir o mundo e nela encontrar o seu alicerce para a sua nova formatação: "enxerte-se em nossas repúblicas o mundo; mas o tronco terá que ser o de nossas repúblicas" (Idem, ibidem).

Esses principais pontos do projeto martiano, que apresentam a necessidade de um rompimento histórico, diferem, nos mesmos quesitos, do pensamento de Luis Alberto Sánchez. Primeiramente, quanto à rejeição de teorias, métodos e conceitos externos é simplesmente impossível pensarmos isso para Sánchez. O autor acreditava que, assim como os homens, os biótipos, a biologia, a cultura e as tradições também sofreram "miscigenações". O mesmo ocorreu com as 'ideias' que se fundiram e se forjaram no desenvolvimento de um pensamento latino-americano, de modo que não seria possível apontar o que fosse europeu, o que fosse saxão, o que fosse précolombiano e assim subsequentemente. Para ele, a busca por uma teoria legítima para a América Latina, sem qualquer influência europeia ou norte-americana, como propunha Martí, era impensável. De maneira irônica, Sánchez escrevia que a única maneira de se realizar tal separação seria regressando aos primórdios dos tempos, ou, como ele mesmo prefere: "ao momento da criação, voltar a Adão e Eva", o que evidentemente jamais poderia ser alcançado (SÁNCHEZ, 1968).

Outro ponto que separa o pensamento de ambos situa-se em torno da posição histórica da América Latina. Para o peruano, o passado do continente estava na América Latina, nas civilizações pré-colombianas, mas também na África, na Ásia e na Europa. Portanto, seria impossível romper com seu passado histórico. Da mesma forma, a América Latina não deveria ser o eixo do mundo, e sim, um protagonista que trabalha em múltipla cooperação, em debate aberto com as outras localidades e blocos de referências mundiais. 
Para finalizarmos, devemos ressaltar alguns pontos que julgamos críticos a respeito do latino-americanismo presente no pensamento de Luis Alberto Sánchez. O latino-americanismo acaba por tornar parcial sua interpretação da América Latina. A ideia de se colocar diante de um debate científico sobre a o continente foi prejudicada por sua necessidade política de afirmá-lo enquanto realidade. Assim, suas explanações, diagnósticos e prognósticos para o continente latino-americano pintavam um futuro fantástico, um presente marcado por um heroico sentimento de superação, frente a um passado de desencontros históricos e subjugação castradora.

Em sua análise esperançosa, o latino-americano que surgiria saberia sobrepor as heranças espanholas e os desmandos da elite criolla, responsáveis pelos males latinoamericanos. A figura do negro, por sua vez, doaria boa parte de sua insubmissão. Esse mestiço, chave do entendimento da realidade latino-americana, surge em seu pensamento como realidade idealizada, provido, até mesmo de um ar messiânico (mesmo que não assumido em sua forma fantástica, como a do mexicano José Vasconcelos em sua Raza Cósmica).

Cabe ainda ressaltar que - mesmo admitindo que a mestiçagem tenha nascido de forma violenta, impositiva e sobreposta, e não de forma harmônica pela singela junção de raças - em Sánchez, o mestiço possuía sim um tom romantizado, uma vez que seria ele "o responsável por trazer harmonia e afinação à sinfonia americana", o que consideramos como algo que soa extremamente utópico, ou um ato de fé. Dessa forma, tal messianismo levaria Sánchez a desenvolver pela América Latina uma espécie de idolatria. Nesse sentido, se a América Latina seria seu "ídolo", podemos dizer que o latino-americanismo se apresentou como sua "religião", algo que Sánchez assumiu de bom grado:

\begin{abstract}
Sei que alguns encontrarão este livro, sobretudo, aqui, no final, um tanto parcial e oratório. Sempre que se tem fé, se é parcial. E o vigor de uma expressão, calorosamente sentida, soa muito à oratória. Sei o proveitoso que é poupar-se e ter tática. Porém, assim não se chega nunca a conclusões. Vivemos uma etapa de afirmações e aprofundamentos. Não importa que a expressão resulte pouco resplandecente e que a erudição se escamoteie. Certa experiência dos livros - escritos, lidos, vividos ou sentidos - me ensinam a desconfiar dos autores que exibem com excesso suas fontes, porque isso denota que não têm segurança do que pensam e quem sabe se o ignoram totalmente. $(1970$, p.152)
\end{abstract}

Talvez o latino-americanismo presente na sua interpretação da América Latina represente que nem sempre o intelectual consiga cumprir a sua difícil missão de manter 
o "uso impessoal da razão nos momentos mais dramáticos de vacilações da 'razão pessoal" (BASTOS; RÊGO, 1999, p.11). Sua identificação com uma realidade de dificuldades, o desenvolvimento às avessas prejudicial ao continente e sua vontade de superá-las marcam o envolvimento sentimental e pessoal do autor com seu objeto. A impossibilidade de captar os diversos sentidos e compreender o continente, resultado da colonização material, ideológica e conceitual de cinco séculos, que, a cada dia, transformam mais a América Latina em um objeto insondável, é transposta pela vontade - e aqui talvez caberia melhor o uso do termo "fé" - pessoal de transformação da realidade e superação das maiores dificuldades do continente, o que, de certa forma, também se apresenta como uma missão do intelectual: se impor diante das desigualdades e das injustiças apresentadas em sua comunidade política.

Esse envolvimento com o seu objeto de análise, ao mesmo tempo em que se apresenta como o seu maior equívoco, também demonstra uma das maiores contribuições para o estudo do latino-americanismo em Luis Alberto Sánchez. Essa contribuição se apresenta na percepção da grande dificuldade de se estabelecer uma identidade sociocultural plausível para a América Latina, tema latente até os dias de hoje. Passamos a possuir essa percepção, a partir do momento em que concebemos Sánchez como um intelectual pertencente a uma linhagem latino-americanista, que elaborou um conjunto de ideias pautado na formulação de uma interpretação da América. No entanto, o seu vínculo com essa linhagem não garante um engessamento de suas análises, como vimos anteriormente.

Ao confrontá-lo com outros autores dessa tradição, veremos que: enquanto Bolívar, devido às limitações de seu momento histórico - lidando com a formação de um novo cenário e imerso em diversas disputas regionalistas - , encontrou uma série de barreiras à percepção da realidade que ainda se constituía; enquanto José Martí, que, ambiguamente, desenhava um desenvolvimento "fora" da modernidade ocidental para a Nuestra América, ainda que com alguns valores europeus, como o romantismo em sua leitura sobre o autóctone; enquanto Rodó via no fortalecimento das heranças latinas um traço positivo para a união latino-americana; e enquanto Haya de la Torre possuía uma interpretação dúbia da América Latina, na medida em que projetava no índio um sentido para a superação da realidade, mas a ser conduzida pela pequena burguesia latinoamericana; Luis Alberto Sánchez acreditava que o caminho a ser trilhado pela América 
Latina, visando a uma verdadeira transformação de suas condições, deveria estar dentro da modernidade, sem, contudo, perder as características de um projeto identitário identidade essa assentada na figura do mestiço.

Justificar a existência da América Latina e propor uma América Latina historicamente viável, como nos evidencia o estudo do latino-americanismo em Luis Alberto Sánchez, requer um envolvimento que ultrapasse o compromisso com a interpretação do real, que supere as barreiras impostas por sua polissemia de sentidos, que reinvente um continente em cada ponto de seu desenvolvimento histórico, especialmente o seu futuro, repleto de expectativas e esperanças, descobrindo assim, em cada nova formulação, um continente possível.

\section{Referências Bibliográficas:}

ANDERSON, Benedict. Comunidades imaginadas: reflexões sobre a origem e a difusão do nacionalismo. São Paulo: Cia da Letras, 2008.

AQUÉZOLO CASTRO, Manuel (Comp.). La polemica del indigenismo. Lima: Mosca Azul, 1976.

BASTOS, E. R.; RÊGO, W. D. L. (Org.). Intelectuais e política. A moralidade do compromisso. São Paulo: Olho Dágua, 1999.

CASTRO, L. Alva. Haya de la Torre y la integración indoamericana. Lima: Instituto Víctor Raúl Haya de la Torre, 1996.

FERREIRA, O. S. Nossa América: Indoamérica. São Paulo: Editora da USP, 1971.

FUNES, Patricia. Salvar la Nación. Intelectuales, cultura y política en los años veinte latinoamericanos. Buenos Aires: Prometeo, 2006.

GARCÍA, Aimer Granados. Congresos e intelectuales en los inicios de un proyecto y de una conciencia continental latinoamericana, 1826-1860. In:

MARICHAL, C. (Comp.). Construcción de la identidades latinoamericanas: ensayos de historia intelectual, siglos XIX y XX. México: Colegio de México, 2004. p. 39-69. .; MARICHAL, C. (Comp.). Construcción de la identidades latinoamericanas: ensayos de historia intelectual, siglos XIX y XX. México: Colegio de México, 2004.

GUERRA, Fraçois-Xavier. Modernidade e independencias. Ensayos sobre las revoluciones hispánicas. $3^{\mathrm{a} e d . ~ M e ́ x i c o: ~ F C E / M A P F R E, ~} 2000$.

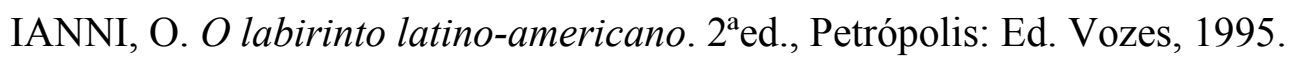


HOBSBAWN, E.; RANGER, T. A invenção das tradições. Rio de Janeiro: Paz e Terra, 1984.

MARTÍ, J. Nossa América. In: RETAMAR R. Fernandez; PEIXOTO, F. José Martí, Nossa América. $2^{\text {a }}$ ed. São Paulo, HUCITEC, 1991.

MIX, Miguel Rojas. Los cien nombres de America. Barcelona: Editorial Lumen, 1991. MORSE, R. O espelho de Próspero. Cultura e ideias nas Américas. São Paulo: Companhia das Letras, 2000.

SALVATTECCI, Hugo Garcia; MIRANDA, Marlene Polo. Luis Alberto Sánchez, la vida del siglo. Caracas: Editora Ayacucho, 1987.

SÁNCHEZ, L. A. ¿Existe América Latina? Examen espectral de América Latina. 2ed. Lima: Ed. Villanueva, 1968.

. Vida y pasión de la cultura en América. 3 ed. Lima: E. Villanueva, 1970.

SMITH, Anthony. Conmemorando a los muertos, inspirando a los vivos. Mapas, recuerdos y moralejas en la recreación de las identidades nacionales. In: Revista Mexicana de Sociología, vol. 60, n.1, p. 61-80, 1998.

THIESSE, Anne-Marie. Ficções criadoras: as identidades nacionais. In: Revista Anos 90, Porto. Alegre, n.15, p.7-23, 2001/2002.

WASSERMAN, C. Percurso intelectual e historiográfico da questão nacional e identitária na América Latina: as condições de produção e o processo de repercussão do conhecimento histórico. In: Revista Anos 90, vol. 10, nº 18, p. 99-123, 2003.

Revista Eletrônica da ANPHLAC, n.12, p. 230-253, jan./jun. 2012. http://revista.anphlac.org.br/index.php/revista 